\title{
Variation in foraging behavior facilitates resource partitioning in a polymorphic cichlid, Herichthys minckleyi
}

\author{
Brook O. Swanson • Alice C. Gibb • \\ Jane C. Marks • Dean A. Hendrickson
}

Received: 29 January 2007 / Accepted: 22 August 2007

(C) Springer Science + Business Media B.V. 2007

\begin{abstract}
We examined foraging behavior (microhabitat use and feeding behavior) in a trophically polymorphic cichlid fish, Herichthys minckleyi, to address several questions regarding resource partitioning in this threatened species. These include: (1) do morphotypes demonstrate different foraging behaviors? (2) do individuals within a morphotype vary in their foraging behavior (e.g. are some individuals specialists, only using a subset of available resources, while other are generalists)? (3) do foraging behaviors vary between isolated pools? (4) do foraging behaviors vary across seasons? We quantified microhabitat use and feeding behavior for over 100 individuals (of two morphotypes) feeding freely in two isolated pools (populations) and across two seasons (winter and summer). We found differ-
\end{abstract}

B. O. Swanson $(\bowtie) \cdot$ A. C. Gibb · J. C. Marks

Department of Biological Sciences,

Northern Arizona University,

P.O. Box 5640, Flagstaff, AZ 86011, USA

e-mail: swansonb@gonzaga.edu

D. A. Hendrickson

Texas Memorial Museum and Section of Integrative

Biology, University of Texas,

Austin, TX 78712, USA

Present address:

B. O. Swanson

Biology Department, Gonzaga University,

AD Box 5,

Spokane, WA 99258, USA ences in foraging behavior between morphotypes and individual specializations within morphotypes; i.e. some individuals specialize on certain food resources by using a few feeding behaviors within a subset of microhabitats, whereas others employ a range feeding behaviors across many microhabitats. Foraging behavior also varied between pools and across seasons. This spatial and temporal variation in foraging behavior and resource use may serve to maintain this polymorphism, as the relative fitness of the each morph may vary over space and time.

Keywords Intra-specific variation · Individual specialization · Feeding ecology .

Trophic polymorphism

\section{Introduction}

Trophic polymorphisms are intraspecific variations in feeding structures that may reduce intra-specific competition (McLaughlin et al. 1999) and facilitate speciation (Darwin 1859; Skúlason and Smith 1995). In addition to morphological differences in feeding structures, morphotypes (morphs) may forage in different microhabitats, exploit different food resources and employ different feeding behaviors (e.g. Robinson and Wilson 1996; Jonsson and Jonsson 2001).

Variation in individual foraging repertoires can also occur within a population regardless of morphology 
(Bolnick et al. 2003). In some cases, even individuals with the same trophic morphology, residing in the same population appear to specialize on specific microhabitats or food resources (Fry et al. 1999). These inter-individual differences in foraging behavior may be important in further decreasing intra-specific competition (Bolnick et al. 2003).

Foraging behavior can also vary at larger scales. For instance, foraging behaviors are related to local resource availability and different behaviors are often demonstrated by spatially distinct groups or populations within a species (Huskey and Turingan 2001; Mittelbach et al. 1992). In addition to this spatial variation, populations often encounter temporal differences in resource availability that lead to changes in resource use (Weliange and Amarasinghe 2003). In the case of either spatial or temporal variation in resource availability, populations often use different foraging behaviors to exploit varying resources.

Herichthys minckleyi, a cichlid fish, is endemic to the spring-fed pools of the Cuatro Ciénegas basin in Coahuila, Mexico and demonstrates at least three distinct trophic morphotypes, or 'morphs' (Kornfield and Taylor 1983). The two most abundant morphs are distinguished by differences in pharyngeal jaw morphology. (The third morph is a piscivorous morph at low frequency in the population.) Different pharyngeal jaw morphologies are at least partially genetically determined and appear to be adaptations for processing different types of food (Liem and Kaufman 1984). In H. minckleyi, the 'papilliform' morph has narrow, needle-like teeth, and gracile pharyngeal jawbones and associated muscles (Liem and Kaufman 1984). This morph feeds primarily on detritus, algae, and soft-bodied invertebrates (Smith 1982) and is efficient at processing vegetation (Hulsey et al. 2005). The 'molariform' morph has large, molar-like teeth, and robust pharyngeal jawbones and associated musculature. In addition to detritus, algae, and soft-bodied invertebrates, this morph also consumes snails and is capable of crushing much harder food items than the papilliform morph (Liem and Kaufman 1984; Hulsey et al. 2005). In addition, evidence suggests that the morphs can segregate by microhabitat in at least one pool habitat in the Cuatro Ciénegas basin (Swanson et al. 2003; Cohen et al. 2005).

This intraspecific variability in morphology, habitat and resource use, make $H$. minckleyi an excellent system to examine complex variation in foraging behavior within a species. In addition, the species is endemic to the threatened Cuatro Ciénegas basin and we hope that information about species ecology will help in the management and conservation of the species and its habitat (see Hendrickson et al. 2007). Here, we quantify the foraging behavior repertoires of individuals of the Cuatro Ciénegas cichlid using two interrelated aspects of foraging behavior: (1) feeding microhabitat, or the location where foraging occurs, and (2) feeding behavior, or the distinct movement pattern used by an individual to capture food items. Using this information we address the following questions: (1) do morphotypes demonstrate different foraging behaviors? (2) do individuals within a morphotype vary in their foraging behavior (e.g. are some individuals specialists, only using a subset of available resources, while other are generalists)? (3) do foraging behaviors vary between isolated pools? (4) do foraging behaviors vary across seasons?

\section{Methods}

Field sites

Foraging behavior was recorded in two spring-fed pools (locally, 'pozas') of the Cuatro Ciénegas basin in Coahuila, Mexico: Mojarral Oeste, (1,298 $\mathrm{m}^{2}$ surface area, $5 \mathrm{~m}$ deep), and Escobedo, $\left(776 \mathrm{~m}^{2}\right.$ surface area, $7 \mathrm{~m}$ deep), both of which contain multiple, distinct microhabitats. In Mojarral Oeste, there is a stromatolite travertine deposit surrounding the large inflow spring, which forms a hard shelf covered with filamentous cyanobacteria and diatoms. The margins of Oeste are covered with thick, soft, flocculent (particulate) material, containing high densities of hydrobiid snails (Kloeppel 2002). Oeste also contains patches of gravel substrate and submerged and emergent water lilies, Nymphea sp.. In Poza Escobedo, most of the benthos is covered with deep, soft flocculent material, but there are also patches of travertine deposit and gravel substrate, and a small amount of emergent vegetation. The flocculent substrate in Escobedo has extremely high densities of hydrobiid snails relative to Oeste and other pools in Cuatro Ciénegas (Kloeppel 2002). Herichthys minckleyi is the dominant and largest fish species in both of these pools, and it co-occurs with several other smaller fish species in both locations (see Hendrickson et al. 2007 
for more detailed descriptions). We choose these pools because they have distinct microhabitats and isolated and confined fish populations.

\section{Behavioral recordings}

Individuals of $H$. minckleyi were captured on 4-5 January 2001 and 30-31 May 2001 using hook and line and gill nets. After capture, fish were anesthetized with twenty drops of clove oil, Eugenia caryophyllata, in approximately 81 of water (Munday and Wilson 1997). Individuals were categorized (based on descriptions by Kornfield and Taylor 1983) into morphotypes by examining pharyngeal teeth through an otoscope. Although pharyngeal tooth morphology represents a continuum, pronounced molariform and papilliform morphology is common and intermediates are relatively uncommon in both habitats. Only individuals with clear molariform or papilliform morphology (most of the individuals captured) were used this study. Fish were measured (mass, standard length), photographed, tagged, allowed to recover in a tub of freshwater for approximately $3 \mathrm{~min}$, and returned to the pool. During tagging, fish were labeled with uniquely numbered, plastic identification tags that were sutured to the epaxial musculature near the anterior base of the dorsal fin using absorbable dental sutures. Absorbable sutures were chosen to minimize impact on fish populations; individuals could be identified in the field for up to 1 week, after which the sutures softened and the tags fell off.

Foraging behavior was recorded in the pools from 7-11 January 2001 and 3-9 June 2001 using a digitalvideo camera (Sony DCR TRV 900 or JVC GR DVL 9800) in an underwater housing. Recordings were made during 1-h periods, four times per day, for five consecutive days in Mojarral Oeste in January (34 molariforms and 36 papilliforms recorded), and alternate days in both pools for 7 days total in June (21 molariforms and 19 papilliforms in Mojarral Oeste recorded; 10 molariforms and 20 papilliforms in Escobedo recorded). Feeding events were recorded using a mixture of 'scan sampling' and 'focal animal sampling' (Altmann 1974) and no individual was ever recorded for more than $1 \mathrm{~min}$ at a time. The observer could not discern morphotype or individual number while recording feeding events, which prevented biased sampling, while individual numbers were obtained from the digital images.
Feeding events were scored from the digital videotapes for (1) microhabitat use and (2) type of feeding behavior. To avoid problems of dependence among the samples, sequential feeding events recorded from a given individual were considered to be a single observation of a behavior within that microhabitat. Additional observations were only recorded when an individual changed either behavior type or microhabitat. Therefore, multiple observations were used for many individuals, but these observations represent independent events because they were spatially and temporally separated (Altmann 1974; Kramer and Schmidhammer 1992). A total of 406 feeding events were analyzed: 159 observations of molariform individuals and 247 observations of papilliform individuals. Five categories were used to identify microhabitat type: (1) water column and surface (column), (2) submerged or emergent vegetation or algae (vegetation), (3) gravel substrates (gravel), (4) hard, travertine shelf (travertine), and (5) soft, flocculent sediments (flock).

A sub-sample of these events $(n=111)$ with exceptionally clear images were visually categorized into four behaviors based primarily on published descriptions of feeding behaviors in cichlids (Liem 1979; Swanson et al. 2003): (1) 'suction feeding,' where the food item appeared to be sucked into the fish's mouth; (2) 'scraping,' where the fish pressed its jaws against a hard surface and removed food items via abrasion; (3) 'diving,' where the fish inserted its head deep into the soft sediments; (4) 'scooping,' where the fish scooped a mouthful of soft sediment from the surface of the substrate with its lower jaw. For these sequences, movements of the head and body during feeding (i.e. feeding kinematics), were measured using a custom measurement program. Kinematic variables included gape (the distance between the upper and lower jaw tips), gape angle (the angle formed by the open jaws), substrate angle (the angle made by the body of the fish relative to the substrate), premaxillary protrusion (the distance the upper jaw protruded anteriorly from the cranium), and substrate depth (the distance the fish penetrated into the substrate). Quantitative comparisons among these variables (taken from this sub-set of the data; not shown) verified that the visual categories were distinct behaviors: based on repeatable, measurable differences among movement patterns (Liem 1979; Swanson et al. 2003). Consequently, additional events 
were categorized visually (using the four feeding behaviors described above) and then added to the overall data set. In this manner, we categorized the microhabitat use and feeding behavior for all 406 feeding events.

\section{Statistical analysis}

A series of $\chi^{2}$ 'goodness-of-fit' tests were conducted to determine if groups of $H$. minckleyi differed in their foraging behavior frequencies (feeding behavior and microhabitat) between morphotypes, pools and seasons. For all $\chi^{2}$ tests, expected contingency tables were constructed using the total number of feeding events in each category (behaviors or microhabitats) and the total number of feeding events for each factor (pool, season, morph). For all foraging behavior comparisons, two $\chi^{2}$ tests were completed: one test compared feeding behaviors and another compared microhabitat use (using the four feeding behavior and five microhabitat categories described above). These $\chi^{2}$ tests determined if the frequencies of observed events differed from the null model of no difference between factors in frequency of behavior or microhabitat use. These tests did not address behavior in relation to resource or habitat availability, but rather whether there were differences in behavior frequencies between groups.

The first set of $\chi^{2}$ tests compared summer observations between the two pools to test for potential differences in foraging behaviors across habitats. Based on the results of this test, all Mojarral Oeste and Escobedo observations were analyzed separately. The second $\chi^{2}$ test assessed potential differences in foraging behavior between winter and summer sampling periods in Mojarral Oeste. Within each pool, and within each season (for the Mojarral Oeste data), additional $\chi^{2}$ tests were used to test for differences in foraging behavior between morphotypes.

To assess the level of individual specialization within the population, we estimated the likelihood of the foraging behavior repertoire of each individual being the same as the population by calculating a standardized likelihood value $(\mathrm{Wi})$ of each individual being randomly drawn from the population mean (Petraitis 1979; Bolnick et al. 2002). This value is related to the $\chi^{2}$ distribution, and allowed us to determine a $p$ value for each individual that estimated the probability of that individual's foraging repertoire being drawn randomly from the population mean. These calculations were done for each distinct group (pool, season, morph), based on the results of the previous $\chi^{2}$ tests (see results below). For example, because we observed differences in overall frequencies of foraging behaviors between morphs, seasons and pools, individuals were only compared to their morph in the pool and season in which they were recorded.

\section{Results}

Although the $\chi^{2}$ tests were conducted in the order: pool comparison, season comparison, morph comparisons, and individual comparisons, morph differences were the focus of this study and will be addressed first. Comparisons in foraging behavior between morphotypes revealed several distinct patterns. For the winter sampling period in Mojarral Oeste, the two morphs showed differences in both microhabitat use and feeding behavior (behaviors; $\chi_{(3)}^{2}=9.52, p<0.05$, microhabitats; $\chi_{(3)}^{2}=9.13, p<0.05$ ). Within this sample, papilliform individuals used the scrape and scoop behaviors more than expected and tended to feed on the travertine substrate. Molariform individuals used the dive behavior more than expected and tended to feed in the flocculent and gravel substrates. In the summer sampling period in Mojarral Oeste, there was no difference in feeding behaviors between morphs $\left(\chi_{(3)}^{2}=3.53, p=0.32\right)$, but there was a difference in microhabitat use $\left(\chi_{(4)}^{2}=12.6, p<0.05\right)$. The molariform individuals used the gravel substrates more than the papilliform individuals, and were never observed feeding in the vegetation or the water column. The summer sampling in Poza Escobedo demonstrated yet another pattern of foraging behavior across morphotypes. Here morphs did not use microhabitats at different frequencies $\left(\chi_{(4)}^{2}=5.67, p=0.22\right.$; Fig. 1a), but did use feeding behaviors at different frequencies $\left(\chi_{(3)}^{2}=9.13, p<0.05\right.$; Fig. 1b). Under these conditions, molariform individuals often employed scooping and suction feeding behaviors, but were never observed using diving or scraping behaviors.

Individuals within each morphotype (within each population) demonstrated individual specialization in both feeding microhabitat and feeding behavior mode. Based on calculations of the standardized likelihood value $(W i)$ for each grouping identified by the $\chi^{2}$ 

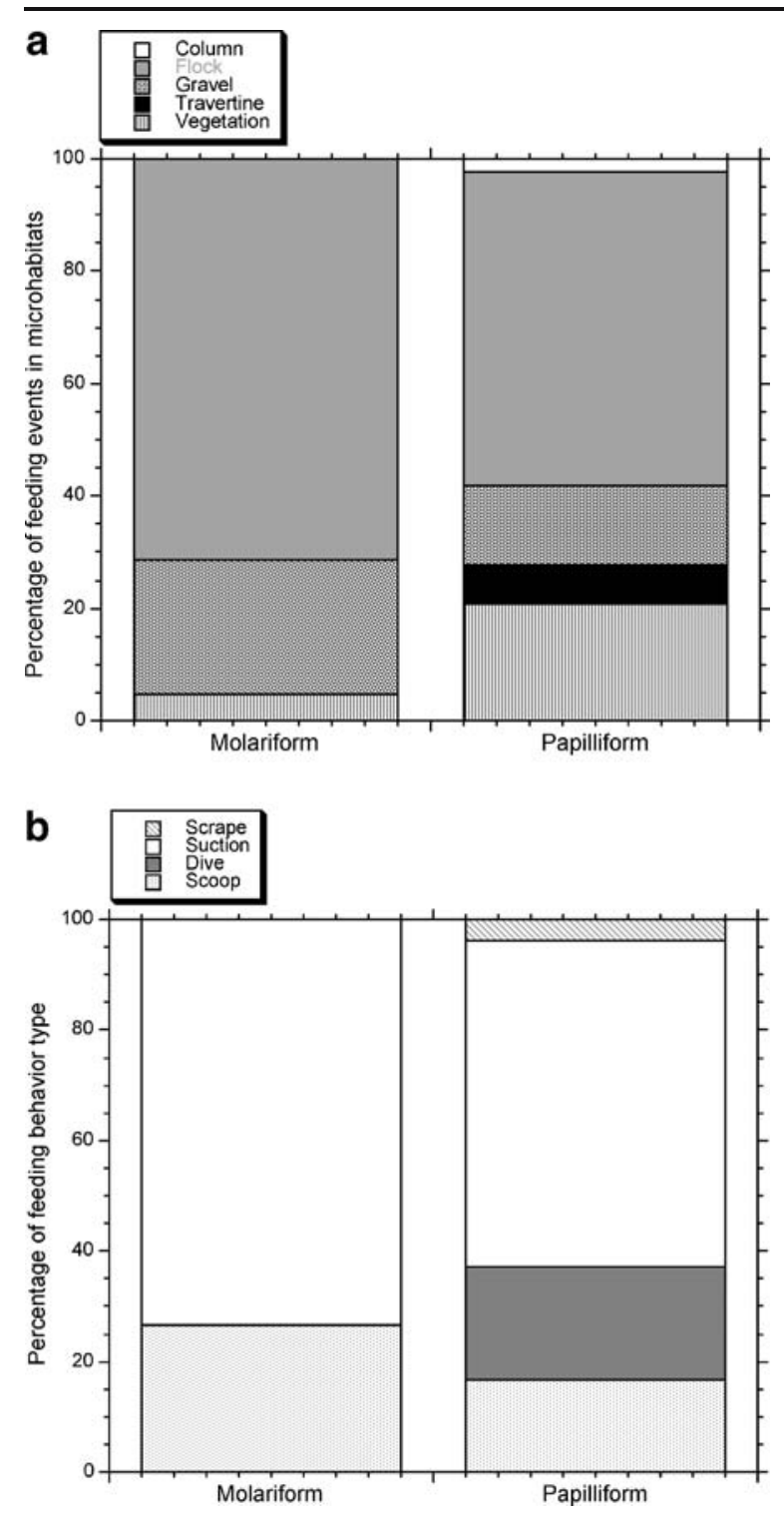

Fig. 1 An example of frequency bar plots comparing microhabitat (a) and behavior type (b) across morphotypes. These are for Poza Escobedo during the summer sampling period. There is no difference in microhabitat use, but the papilliforms used the dive and scrape behavior at a higher frequency than the molariforms. See text for explanations of microhabitat types and behaviors

analysis, 16 of the 63 individuals used in the analysis significantly diverged from the average population frequency of microhabitat or feeding behavior use. In fact, most (7 out of 10) of the groups analyzed demonstrated some degree of individual specialization. A finding of no significant individual specialization could be due to an individual demonstrating foraging behaviors at the same frequencies as the

group, or could be simply a consequence of a low sample size for that individual. Thus, this method will tend to underestimate individual specialization.

Comparisons of foraging behaviors between pools (between Escobedo and Mojarral Oeste in the summer) revealed that fish feed in different microhabitats across the two pools $\left(\chi_{(4)}^{2}=27.60, p<0.05\right.$; Fig. 2a) and use feeding behaviors at different frequencies $\left(\chi_{(3)}^{2}=23.22, p<0.05\right.$; Fig. 2b). Fish used more of the scooping behavior than expected in Escobedo and more of the scraping behavior in Mojarral Oeste. In Mojarral Oeste, fish often fed on the large travertine shelf. In Escobedo, fish often fed in the abundant flocculent substrates.

Seasonal variation in foraging behavior was also sometimes evident. In Mojarral Oeste, microhabitat use did not appear to change across seasons $\left(\chi_{(4)}^{2}=\right.$ 4.7, $p=0.45$; Fig. 3a). Feeding behaviors were employed at different frequencies between seasons $\left(\chi_{(3)}^{2}=13.71, p<0.05\right.$; Fig. $\left.3 b\right)$ : fish used more scraping and diving behaviors during the summer, whereas they used more suction feeding during the winter.

\section{Discussion}

In Herichthys minckleyi, foraging behavior varies markedly between two trophic morphotypes, but also varies among individuals of a morphotype, across space (populations within two pools) and over time (two seasons in one pool). The hypothesis that trophic morphotypes behaviorally enhance resource partitioning was supported by our finding that the two morphs differed in some aspect of foraging under all of the conditions we examined. However, the amount of behavioral partitioning varied both temporally and spatially. Fish in Mojarral Oeste in the winter, for example, demonstrated morphotype differences in both microhabitat use and feeding behavior. In the Mojarral Oeste summer sample, morphs still fed in different microhabitats, but there was no difference in the frequency of use of feeding behaviors. This suggests that although the morphs may still partition the habitat spatially, during this time of the year morphs may be exploiting similar food resources that are seasonally abundant within many microhabitats (e.g., soft-bodied invertebrates). In contrast, in Escobedo, morphs did not use microhabitats differently, 

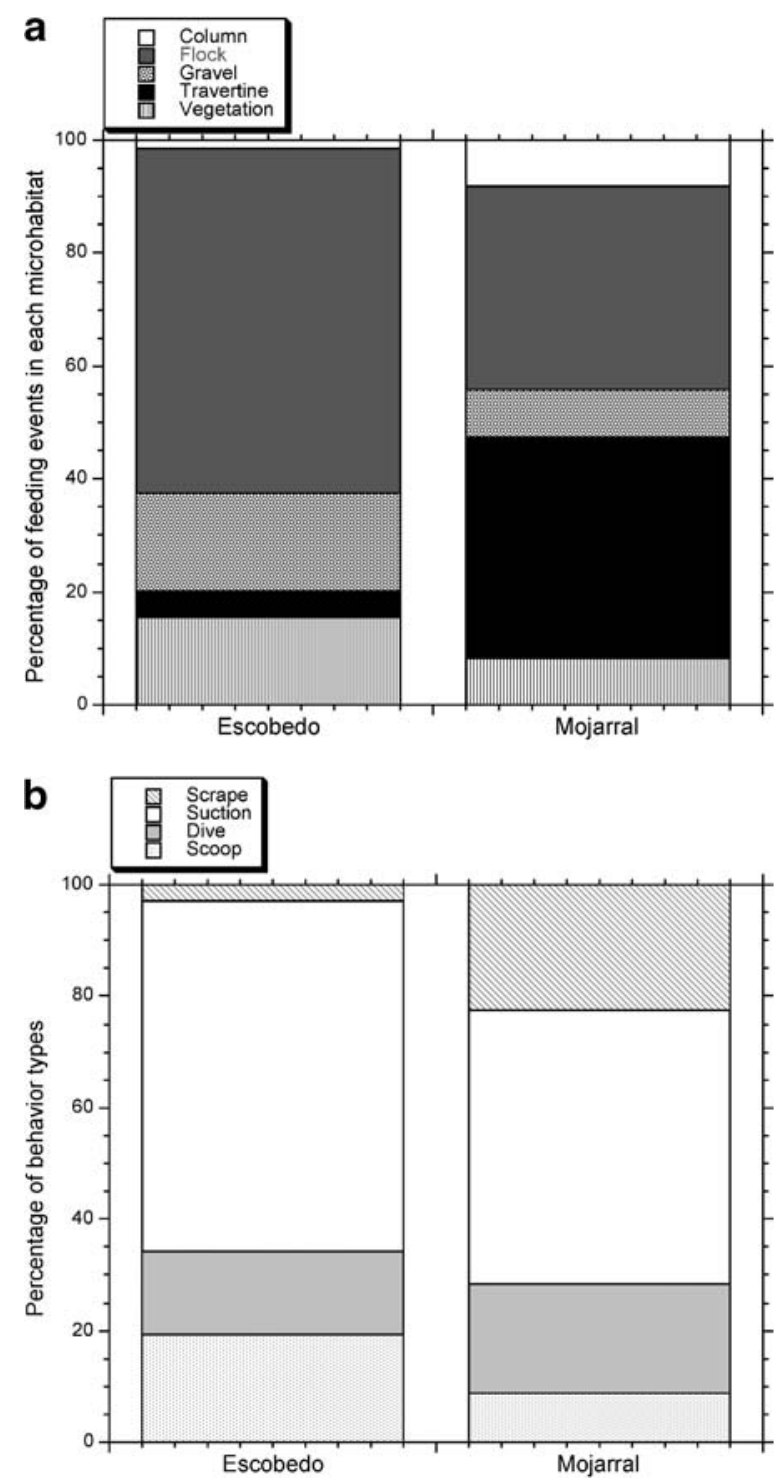

Fig. 2 Frequency bar plots comparing (a) microhabitat use and (b) feeding behavior type across habitats between the Mojarral Oeste and Poza Escobedo sites during the summer sampling period. Foraging in Escobedo was more likely in the soft flocculent microhabitat and fish were more likely to use the scooping behavior. In Mojarral Oeste, foraging was more likely on the hard travertine microhabitat and fish were more likely to exhibit the scraping behavior. See text for explanations of microhabitat types and behaviors

but they did employ different feeding behaviors within microhabitats. We note that Escobedo is dominated by the soft flocculent microhabitat (Kloeppel 2002) and suggest that fish may be compelled to forage with in this microhabitat. Morphs did employ feeding behaviors at different frequencies, suggesting that when microhabitat choice is limited, morphs can

continue to segregate food resources by employing different feeding behaviors. Combined, the data from the two pools provide a complex picture of behavioral variation across morphotypes of $H$. minckleyi. Papilliform and molariform morphotypes can partition resources based on microhabitat, or feeding behavior within microhabitat, or both - and these patterns vary across both space and time. In spite of the differences in microhabitat and behavior use across seasons and
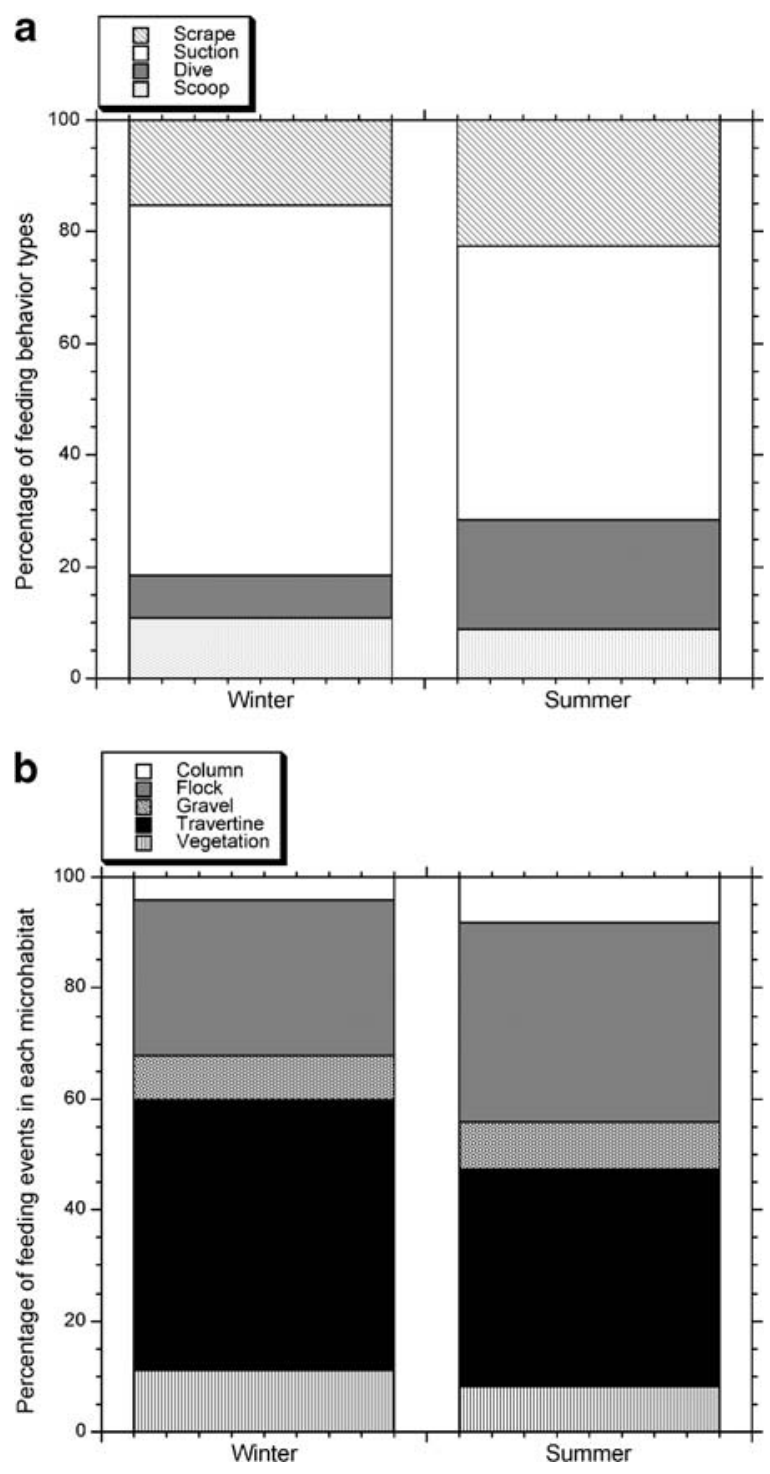

Fig. 3 Frequency bar plot comparing (a) behavior type use and (b) microhabitat use across seasons between winter and summer sampling periods in Mojarral Oeste. In the summer fish were observed to perform the dive and scrape behavior more than in the winter. Microhabitat use was not different. See text for explanations of microhabitat types and behaviors 
pools, we note that morphs consistently appear to partition resources via some aspect of foraging behavior.

Individual specialization independent of morphology may allow further resource partitioning both within and between morphs. We found evidence of individual specialization for particular microhabitats or behaviors (or both) across the population. Although some individuals demonstrate a foraging repertoire that is indistinguishable from the overall repertoire for the group, others appear to be specialists that were observed multiple times feeding primarily in a single microhabitat or employing a single feeding behavior. This individual specialization has in fact been suggested as a mechanism for the evolution of trophic polymorphism, where individuals in a monomorphic population may select feeding behaviors that enable them to exploit very small morphological variations. If a particular foraging behavior becomes associated with a certain morphological variation, and there is a genetic basis for the variation, this could ultimately yield divergent morphotypes (Skúlason and Smith 1995; McLaughlin 2001).

We suggest that observed differences in foraging behavior between pools are related to the availability of microhabitats within the pools and the food resources found within those microhabitats. The bottom of Escobedo is almost entirely covered with deep, soft flocculent sediments that contain very high snail densities (Kloeppel 2002); both trophic morphotypes fed more often in the flocculent substrate in Escobedo than in Mojarral Oeste. Mojarral Oeste has more travertine substrate than Escobedo and lower snail densities in the flocculent substrate (Kloeppel 2002). Variation in habitat availability may require individuals to use different foraging behaviors to exploit the foods present in the most prevalent microhabitats.

We also observed seasonal differences in foraging behavior in Mojarral Oeste. Other aquatic systems have been shown to demonstrate changes in foraging patterns that correspond to seasonal changes in food abundance (David and Closs 2003). However, we did not initially expect Cuatro Ciénegas pools to vary in this manner, due to nearly invariant (and warm) temperatures (Dinger 2001; Kloeppel 2002). There is little seasonal variation in abundance or diversity of aquatic insects, amphipods, polychaetes (Dinger 2001), or snails (Kloeppel 2002) in Cuatro Ciénegas pools. However, changes in photoperiod may trigger other seasonal changes in the pools, such as variation in the abundance of particular life history stages of aquatic invertebrates, or changes in the primary productivity of the pools that may affect the foraging ecology of $H$. minckleyi. More data will be needed to test these hypotheses.

Because we have only a single sample for each, we cannot conclude that the differences we observed between pools or seasons are consistently present across other pools in the system or across years. However, the data do demonstrate complex variability in the system. This measurable variation in resource use across space and time suggests a complex, dynamic pattern, which may explain the long-term maintenance of morphological variation within $H$. minckleyi. Morphotypes may have different relative fitnesses in different pool habitats (based on the different resource availabilities). Thus habitat variability may help maintain morphological differences among individuals of the species, because either morphotype could have an advantage in some subset of the species range (Snyder and Chesson 2003). The fact that different morph ratios are found in different Cuatro Ciénegas pools (Stephens 2002) supports this idea. Variation in resource availability over time may similarly help maintain polymorphism in the population (Roughgarden 1983; Snyder and Chesson 2003).

Our findings also have implications for the conservation of $H$. minckleyi (considered in danger of extinction) and its threatened habitat. There is currently a management plan in place for the species (Instituto Nacional de Ecología - SEMARNAP. 1999. Programa de Manejo del Área de Protección de Flora y Fauna Cuatrociénegas. Instituto Nacional de Ecología, México, D.F.). However, this plan does not directly address the maintenance of habitat diversity on several spatial scales. We suggest that the maintenance of this complex habitat diversity may be critical for the survival of the species.

Acknowledgements We thank S. Skúlason and B. Kristjánsson for suggesting several of the analyses used here. F. García de León helped us obtain permits required to carry out our research (Secretaría de Agricultura, Ganadería, Desarrollo Rural, Pesca y Alimentación, Comisión Nacional de Acuacultura y Pesca, Dirección General de Ordenamiento Pesquero y Acuícola: 180202-613-03-050 and amendments, 041099-21303 and 140102-613-03). K. Cummins, H. Kloeppel, C. Williamson, M. Hess, and A. Cohen assisted with our field studies. E. Dinger and H. Kloppel provided invertebrate 
abundance data and W.L. Montgomery provided equipment. D. Bolnick provided the program that determined levels of individual specialization and assisted with its use. L. FerryGraham and L. Drickamer provided helpful comments on early drafts of the manuscript. A NAU intramural grant and NSF IBN 0002301 to ACG, EPA Star Fellowship U-91591901 to BOS, and an Ecosystem Research Program grant from The Nature Conservancy to JCM and DAH, and NSF EB 0074876 POWRE to JCM supported this work.

\section{References}

Altmann J (1974) Observational study of behavior: sampling methods. Behavior 48:227-265

Bolnick DI, Yang LH, Fordyce JA, Davis JM, Svanback R (2002) Measuring individual-level resource specialization. Ecology 83:2936-2941

Bolnick DI, Svanback R, Fordyce JA, Yang LH, Davis JM, Hulsey CD, Forister ML (2003) The ecology of individuals: incidence and implications on individual specialization. Am Nat 161:1-28

Cohen AE, Hendrickson DA, Parmesan C, Marks JC (2005) Habitat segregation among trophic morphs of the Cuatro Ciénegas cichlid (Herichthys minckleyi). Hidrobiológica 15:169-181

Darwin CR (1859) On the origin of species by means of natural selection. J. Murray, London

David BO, Closs GP (2003) Seasonal variation in diel activity and microhabitat use of an endemic New Zealand streamdwelling galaxiid fish. Freshw Biol 48:1765-1781

Dinger EC (2001) Aquatic invertebrates of Cuatro Ciénegas, Coahuila, Mexico and effects of fish on stromatolite invertebrate assemblages. Masters Thesis, Northern Arizona University, Flagstaff, pp 61

Fry B, Mumford PL, Tam F, Fox DD, Warren GL, Havens KE, Steinman AD (1999) Trophic position and individual feeding histories of fish from Lake Okeechobee, Florida. Can J Fish Aquat Sci 56:590-597

Hendrickson DA, Marks JC, Moline AB, Dinger E, Cohen AE (2007) Combining ecological research and conservation: a case study in Cuatro Ciénegas, Mexico. In: Stevens L, Meretsky VJ (eds) Every last drop: ecology and conservation of North American desert springs. University of Arizona Press, Tucson

Hulsey CD, Hendrickson DA, García de León FJ (2005) Trophic morphology, feeding performance and prey use in the polymorphic fish Herichthys minckleyi. Evol Ecol Res 7:1-22

Huskey SH, Turingan RG (2001) Variation in prey resource utilization and oral jaw gape between two populations of largemouth bass, Micropterus salmoides. Environ Biol Fishes 61:185-194

Jonsson B, Jonsson N (2001) Polymorphism and speciation in Arctic char. J Fish Biol 58:605-638

Kloeppel H (2002) Molluscivore (Herichthys minckleyi) effects on snail (Mexipyrgus carranzae) densities and size in
Cuatro Ciénegas, Mexico, MS Thesis, Northern Arizona University, Flagstaff, pp 33

Kornfield I, Taylor JN (1983) A new species of polymorphic fish, Cichlasoma minckleyi, from Cuatro Ciénegas, Mexico (Teleostei: Cichladae). Proc Biol Soc Wash 96:253-269

Kramer M, Schmidhammer J (1992) The chi-squared statistic in ethology: use and misuse. Anim Behav 44:833-841

Liem KF (1979) Modulatory multiplicity in the feeding mechanism in cichlid fishes, as exemplified by the invertebrate pickers of Lake Tanganyika. J Zool 189:93-125

Liem KF, Kaufman LS (1984) Intraspecific macroevolution: Functional biology of the polymorphic cichlid species Cichlasoma minckleyi. In: Echelle AA, Kornfield I (eds) Evolution of species flocks. University of Maine at Orono Press, Orono, Maine, pp 203-215

McLaughlin RL (2001) Behavioral diversification in brook charr: adaptive responses to local conditions. J Anim Ecol 70:325-337

McLaughlin RL, Ferguson MM, Noakes DLG (1999) Adaptive peaks and alternative foraging tactics in brook charr: evidence of short-term divergent selection for sit-andwaiting and actively searching. Behav Ecol Sociobiol 45:386-395

Mittelbach GG, Osenberg CW, Wainwright PC (1992) Variation in resource abundance affects diet and feeding morphology in the pumpkinseed sunfish (Lepomis gibbosus). Oecologia 90:8-13

Munday PL, Wilson SK (1997) Comparative efficacy of clove oil and other chemicals in anaesthetization of Pomacentrus amboinensis, a coral reef fish. J Fish Biol 51:931-938

Petraitis PS (1979) Likelihood measures of niche breadth and overlap. Ecology 60:703-710

Robinson BW, Wilson DS (1996) Genetic variation and phenotypic plasticity in a trophically polymorphic population of pumpkinseed sunfish (Lepomis gibbosus). Evol Ecol 10:631-652

Roughgarden J (1983) Competition and theory in community ecology. Am Nat 122:583-601

Skúlason S, Smith TB (1995) Resource polymorphisms in vertebrates. Trends Ecol Evol 10:366-370

Smith DC (1982) Trophic ecology of the cichlid morphs of Cuatro Ciénegas, Mexico. M.S. thesis, University of Maine at Orono, Orono

Snyder RE, Chesson P (2003) Local dispersal can facilitate coexistence in the presence of permanent spatial heterogeneity. Ecol Lett 6:301-309

Stephens MJ (2002) Pharyngeal morphology and spatial and temporal variation in trophic composition in the polymorphic cichlid, Herichthys minckleyi (Teleostei: Cichlidae) from the Cuatro Ciénegas Basin, Mexico. Masters Thesis, Southwest Texas State University, San Marcos pp 61

Swanson BO, Gibb AC, Marks JC, Hendrickson DA (2003) Trophic polymorphism and behavioral differences decrease intra-specific competition in a cichlid, Herichthys minckleyi. Ecology 84:1441-1446

Weliange WS, Amarasinghe US (2003) Seasonality in dietary shifts in size-structured freshwater fish assemblages in three reservoirs of Sri Lanka. Environ Biol Fishes 68:269-282 